\title{
Competition and cooperation: Libraries and publishers in the transition to electronic scholarly journals
}

\author{
Andrew Odlyzko \\ AT\&T Labs - Research \\ Florham Park, New Jersey 07932 \\ amo@research.att.com
}

January 19, 1999

\begin{abstract}
The conversion of scholarly journals to digital format is proceeding rapidly, especially for those from large commercial and learned society publishers. This conversion offers the best hope for survival for such publishers. The infamous "journal crisis" is more of a library cost crisis than a publisher pricing problem, with internal library costs much higher than the amount spent on purchasing books and journals. Therefore publishers may be able to retain or even increase their revenues and profits, while at the same time providing a superior service. To do this, they will have to take over many of the function of libraries, and they can do that only in the digital domain. This paper examines publishers' strategies, how they are likely to evolve, and how they will affect libraries.
\end{abstract}




\section{Introduction}

A specter is haunting the publishing industry. It is the specter of Encyclopaedia Britannica. My first paper on electronic publishing [Odlyzko1] cited Encyclopaedia Britannica as an example of a formerly flourishing business that fell into trouble in just a few years by neglecting electronic media. Since that time, Encyclopaedia Britannica has collapsed, and was sold to Jacob Safra, who is investing additional funds to cover losses and revamp the business [Melcher]. The expensive sales force has been dismissed, and while print versions can still be purchased from bookstores, the focus is on electronic products. This collapse occurred even though Encyclopaedia Britannica had more than two centuries of tradition behind it, and was by far the most scholarly and best known of the English-language encyclopedias. In the apt words of [EvansW],

Britannica's downfall is more than a parable about the dangers of complacency. It demonstrates how quickly and drastically the new economics of information can change the rules of competition, allowing new players and substitute products to render obsolete such traditional sources of competitive advantage as a sales force, a supreme brand, and even the world's best content.

This paper concentrates on scholarly journals. Not only that, but it will not deal with journals such as Science or IEEE Spectrum, which are distributed to tens or hundreds of thousands of readers. It will concentrate on the low-circulation journals that are sold primarily to libraries, and typically have about a thousand subscribers. These are the journals that bring in the bulk of revenues to scholarly publishers, and are the source of the research library crisis. Still, the Encyclopaedia Britannica example will be used several times in analyzing these journals. The markets are different, but there are many similarities.

A few years ago there was considerable skepticism whether electronic journals were feasible at all. A large part of [Odlyzko1] was therefore devoted to demonstrating that Licklider [Licklider] was right in the early 1960s in predicting that by the late 1990s, computing, communications, and storage technologies would be adequate for handling the scholarly literature. By now, most such doubts

have been dispelled (although there are still exaggerated concerns about durability of digital storage as well as technical standards). It is also widely accepted that electronic journals are desirable and inevitable. Therefore we see rapid growth of digital material. Scholarly journals that exist only in electronic formats continue to proliferate. However, since they started from a low base, they still cover a small fraction of the literature. The dominant electronic journals (if not in absolute numbers, then 
certainly in amount of peer-reviewed material) are digital versions of established print serials. (See [ARL, HitchcocCH] for latest estimates of the electronic marketplace.) The largest scholarly publisher, Elsevier, will soon have all its approximately 1200 journals available electronically. Professional societies, such as the ACS, APS, AMS, and SIAM, also have either already created electronic versions of all their research journals, or are in the process of doing so. The question of whether most scholarly journals will be electronic or not is thus settled.

While it is now widely accepted that scholarly journals have to be electronic, how they are to be delivered, and especially at what price, remains to be decided. This article examines the current practices by publishers, both commercial and professional society ones, and their likely evolution and impact on libraries.

Some features of the electronic offerings from established publishers (such as offering only bundles of journals, without a chance to purchase individual ones) are causing controversy among scholars and librarians. The subtitle of the article [Kiernan1] describes the mixture of reactions well: "Some see a way to meet professors' needs; others say publishers are protecting profits." There is no doubt that the publishers' primary motive is protection of revenues and profits. This is true for both commercial and learned society publishers. Still, this article argues that professors' needs are likely to be better satisfied by these new electronic offerings than by traditional print journals. However, for the publishers to protect their revenues and profits, they will have to usurp much of the role and resources of libraries. Further, publishers' success is likely to retard the development of an even more efficient system.

Encyclopaedia Britannica was vulnerable largely because it had an enormously bloated cost structure. The $\$ 1,500$ to $\$ 2,500$ that purchasers paid for each set included a couple of hundred dollars for the printing, binding, and distribution. Most of the rest was for the sales force and general administrative overhead. The vaunted editorial content apparently amounted to well under 10 percent of the total price. That is what allowed $\$ 50 \mathrm{CD}-\mathrm{ROM}$ encyclopedias to compete. They did not have the same quality of content, nor the nicely printed volumes, but they did have superior searchability, portability, and an irresistible price.

It is important to note that after some abortive attempts to sell first $\$ 1,200$, then $\$ 300 \mathrm{CD}-\mathrm{ROMs}$, Encyclopaedia Britannica is now offering its CD-ROMs for $\$ 125$ or even less. It is not known publicly what its total budget or internal cost allocations are, but it appears safe to say that the entire encyclopedia industry is spending much more on content than it used to. At Britannica, editorial staff reportedly has increased by over 25 percent. Further, usage of encyclopedias has probably increased substantially. While most of the CD-ROM versions are hardly ever used (which was also true of the paper editions, 
of course), there are tens of millions of them, many more than the print encyclopedias. This means that total usage is surely up. Universities that subscribe to the online version of the Encyclopaedia Britannica report that usage is far higher than it ever was for the printed versions [Getz].

As with Encyclopaedia Britannica, the main effect of new technologies on other parts of the publishing industry will be elimination of costs that once were unavoidable. Spending on content will go up. Total profits, which many finger as the culprit in the library crisis, may also increase. (It was noted in [Odlyzko1] that while revenues of the World Book encyclopedia went down when it switched to a CD-ROM format, profits grew.) However, the entire information industry is likely to become much more efficient, with more resources devoted to the intellectual content that matters.

The current scholarly journal system is full of unnecessary costs. The ones that have attracted the most attention in the past were those associated with publishing. The main traditional functions of publishers, in which they handled copy editing, production, and distribution of material provided to them for free by scholars, are mostly obsolete. The difference in quality between the manuscripts that scholars can produce themselves, and the final printed journal versions, has decreased almost to the vanishing point with the arrival of easy to use computerized typesetting. (Here I am referring to copy editing and other tasks performed by professionals at publishers. Peer review is another matter. It was and continues to be done gratis by scholars, so that even if it is facilitated by publishers today, it can be performed without them.)

To a large extent publishers are responding to cuts in subscriptions of large (and therefore expensive) journals by launching smaller, more specialized serials. These are often treated with much less care, so they are not much better in quality of presentation than camera-ready journals. Furthermore, they often have laughably small circulations (such as the figure of 300 or lower cited by a publisher [Beschler]). Thus the current scholarly journal system is becoming dysfunctional.

To survive in the long run, publishers will need to move towards provision of intellectual value (such as that provided by the staffs of reviewing journals). That is a hard task, requiring new skill sets, and often new personnel. What keeps the publishers' situation from being hopeless is the tremendous inertia of the scholarly community, which impedes the transition to free or inexpensive electronic journals. Another factor in the publishers' favor is that there are other unnecessary costs that can be squeezed, namely those of the libraries. Moreover, the unnecessary library costs are far greater than those of publishers, which creates an opportunity for the latter to exploit and thereby to retain their position.

Section 2 briefly reviews the economics of scholarly journals. Section 3 discusses the basic strategy that established publishers are following in moving to electronic journals. Section 4 concentrates on 
some features of the current electronic journal pricing and licensing policies. Finally, Section 5 offers some speculation about the future.

\section{Economics and technology}

This section reviews the basic economic facts about scholarly journal publishing. They were first presented in [Odlyzko1] and then in greater detail (and with more data about electronic journals, based on more experience) in [Odlyzko4]. See also [TenopirK].

Conventional print journals bring in total revenues to publishers of about $\$ 4,000$ per article. On the other hand, there are many flourishing electronic journals that operate without any money changing hands, through the unpaid labor of their editors (and with a trivial implicit subsidy by the editors' institutions that provide computers and network connections). There is still some question whether this model can scale to cover most of peer-reviewed literature and satisfy scholar's needs. Even if the totally free journals will not suffice, experience has shown that quality that is perfectly adequate for most readers can be produced in the electronic environment for less than $\$ 400$ per article [Odlyzko4]. Such costs can be recovered either through subscription fees or charges to authors, and both models are being tried.

Journal subscription costs are only one part of the scholarly information system. As was pointed out in [Odlyzko1], internal operating costs of research libraries are at least twice as high as their acquisition budgets. Thus for every article that brings in $\$ 4,000$ in revenues to publishers, libraries in aggregate spend $\$ 8,000$ on ordering, cataloging, shelving, and checking out material, as well as on reference help. The scholarly journal crisis is really a library cost crisis. If publishers suddenly started to give away their print material for free, the growth of the literature would in a few years bring us back to a crisis situation.

It is important to emphasize the point about the cost of libraries. The $\$ 4,000$ per article is rough estimate (see [Odlyzko1, Odlyzko4, TenopirK]) and one can argue that the precise figure should be higher or lower. On the other hand, the exact dollar figures for the 120 members of the Association of Research Libraries, which includes most of the large research libraries in the U.S. and Canada, do show that purchases of books, journals, and other materials make up rather consistently about a third of their budgets, and have done so for years [ARL]. The other two thirds goes overwhelmingly for salaries and wages of librarians and support staff, with a small fraction for items such as binding. The table below shows the breakdown of library expenditures at several universities during the 1996-97 academic year, taken from the comprehensive statistics collected by the ARL and available online at [ARL]. (Harvard 
has the world's highest library budget.)

$\begin{array}{lcrrc} & \text { circulation } & \text { staff } & \text { purchases } & \text { total budget } \\ \text { Brown } & 0.3 \mathrm{M} & 240 & \$ 5.0 \mathrm{M} & \$ 14.8 \mathrm{M} \\ \text { Harvard } & 1.4 \mathrm{M} & 1182 & \$ 17.5 \mathrm{M} & \$ 70.9 \mathrm{M} \\ \text { Ohio State } & 1.5 \mathrm{M} & 423 & \$ 8.6 \mathrm{M} & \$ 22.1 \mathrm{M} \\ \text { Princeton } & 0.6 \mathrm{M} & 384 & \$ 9.2 \mathrm{M} & \$ 24.9 \mathrm{M}\end{array}$

This division of costs has held for a long time. For example, in the 1996-97 academic year, Harvard spent $24.7 \%$ of its library budget on acquisitions, whereas in $1981-82$ it spent $27.5 \%$ ( $\$ 5.8 \mathrm{M}$ out of $\$ 21.1 \mathrm{M})$

The ARL numbers substantially underestimate the internal costs of libraries, since they include neither the costs of the buildings, nor of building maintenance, nor of employee fringe benefits. In many cases those numbers also fail to include the costs of library automation systems. If those additional costs were to be included, costs of acquisitions might turn out to be under a quarter of the total costs of the library system [Getz]. Thus, even though much of the cost to a library that is associated with a journal is incurred in the future, in preserving the issues and making them accessible, it seems safe to say that the internal costs of the library associated with that journal are at least twice the purchase price.

The high internal costs of libraries come from the need to provide information about, and easy access to huge collections of material that are used infrequently at any single place. As an example, suppose that we ignore all the other activities of the Harvard libraries, and allocate the entire library cost to circulating items. We would then discover that circulating the 1.4 million items that were borrowed (out of 13.6 million volumes in the Harvard collection [ARL]) cost around \$50 each. By comparison, there are commercial services (aimed at allowing publishers to reprint books in extremely small runs) that will digitize a book for a one-time fee of $\$ 100$ to $\$ 150$, and then print individual copies of a 300-page book for about $\$ 5$ [NYT]. That is an order of magnitude reduction in cost. Of course, this comparison ignores all the other function of the library, but it does demonstrate the dramatic cost savings that are becoming possible if one can cut back on the acquisition and management of a physical collection.

The high cost of operating libraries is giving publishers a chance to maintain their revenues. Standing at the level of $\$ 4,000$ articles, they are naturally reluctant to jump into the chasm of free or at most $\$ 400$ articles. Instead, they are enviously eyeing the $\$ 8,000$ per article spent by libraries. They are responding, either by careful design, or through competitive instinct, in ways that should reduce the costs of the total system by decreasing the role and cost of libraries. To the extent they succeed, this should produce a much superior scholarly information system, although still an unnecessarily expensive one. 
There have been occasional proposals that libraries take over the functions of publishers. Given the unnecessarily high price structure of publishers, such a course is conceivable. However, what is much more likely to happen in the competition for resources between libraries and publishers is that it will be the publishers who will come out ahead. There are cultural, economic, technological, and legal reasons for this prediction:

1. There are fewer publishers, so it is easier for them to mount electronic publishing efforts on a large scale,

2. Publishers are more used to competition than librarians, who stress cooperation,

3. Publishers control copyrights, and thus conversion of old material (crucial for reducing library costs) cannot be carried out without their cooperation, and, perhaps most important,

4. The publishers' target is more inviting: there is more than twice as much resources for them to go after as there is for librarians.

If the scholarly publishing business were efficient and run for the benefit of the scholarly enterprise, both libraries and publishers would have to shrink rapidly. However, this business is anything but efficient. A major contributor to this inefficiency is academic inertia. As shown in the discussion of rates of change in [Odlyzko6], academia is among the slowest to change in general. Further, scholarly publication is a sufficiently small part of research life that it does not attract much attention. Libraries usually consume $3 \%$ to $4 \%$ of university budgets, so any savings that might be realized from library cutbacks would not make a dramatic difference to total spending. (Among the academic ARL members, library spending averages about $\$ 12,000$ per full time faculty member [ARL].) Furthermore, library buildings, often the most prominent on campus, easily attract donors who like to see their names immortalized on such central facilities.

The most convincing demonstration of scholarly inertia is the reaction (or the lack of it) to the Ginsparg preprint archive. Starting in 1991, it has become the fundamental communication method for a growing roster of fields, starting with theoretical high energy physics, later spreading to other areas of physics, and now also to computer science and mathematics [Ginsparg]. It is a sterling example of how technology can lead to a sudden, profound, and beneficial transformation. Yet in 1998, this archive still processed only 24,000 submissions, which is substantial (about half of the volume of all mathematics papers published that year), but small compared to the perhaps 2 million papers in all 
STM (science, technology, medicine) areas. The attractions of the archive are great. It transforms the mode of operation of any community of scholars that embraces it, and the transition is invariably oneway, as not a single group has abandoned it. It quickly becomes the dominant mode of communication inside any group that embraces it. However, in spite of extensive publicity, it has not swept scholarly communication yet. It appears that there were special cultural factors that led to the quick adoption of the archive by Ginsparg's own community of theoretical high energy physicists (primarily the reliance on massive mailings of preprints), and it has been a struggle for pioneers in other areas to duplicate the process. There are still many areas (especially in chemistry and medicine) where not just preprint archives, but preprints themselves, are rare, and in which prestigious journals get away with policies that forbid any formal consideration of a paper that has been circulated in preprint form.

The significance of the Ginsparg archive is two-fold. On one hand, it shows that scholars can embrace new technology in a short period and derive enough benefit that giving it up becomes unthinkable. On the other hand, it also shows that it requires a substantial critical mass or an external push in an area to make the transition. In most of the STM fields, this critical mass is not present yet.

A Ginsparg-style centralized preprint archive (or a decentralized system like MPRESS from the European Mathematical Society) is not compatible in the long run with an expensive journal publishing operation that collects $\$ 4,000$ per article. "Available information determines patterns of use" in the apt words of Susan Rosenblatt [Odlyzko5], and if the basic preprints are available for free, few will pay a fortune for slight enhancements, which is all that current journals offer. The question is what is meant by "the long run." The discussion in [Odlyzko6] as well as that above about the Ginsparg archive shows that academia moves at a glacial pace. Even in Ginsparg's own theoretical high energy physics community, most researchers still publish their papers in conventional print journals (although a few senior ones have given up the practice on the grounds that it does not serve to propagate their results). Thus if academia were left to itself, the current journal system might continue to stumble along for a couple of decades until the subversive effect of preprints would make it clear the system was not worth its cost.

In the discussion on diffusion of new technologies in [Odlyzko6], many rapid transitions were identified with the presence of forcing agents, people or institutions that can compel action. The prediction of [Odlyzko1] was that a collapse of the existing print journal system would come when academic decision makers (presidents, deans, ...) realized that this system was superfluous, and go to departments with offers of the type "Would you rather stay with the existing library system at $\$ 12,000$ per head, or would you be willing to cut that back to $\$ 6,000$ per head, and use the savings for salaries, travel, ...?” I 
think this is still the most likely scenario for change, but that it will involve abandonment of print and cutbacks in libraries, and less of a cutback at publishers. Publishers, who have been scared of electronic publishing, are likely to become forcing agents, and speed the transformation.

\section{The demise of print journals}

Most established publishers have already created or are creating electronic versions of their scholarly print journals. Often they are offering these digital editions at no extra cost to subscribers to the print versions. In some cases, institutions that forego the print version receive a modest discount.

A coherent strategy for the publishers should contain two additional steps in the future. The first step is to eliminate print editions entirely. (This has not yet been announced by any major publisher.) The second one is to convert the old issues to digital form, either themselves or through organizations like JSTOR [Guthrie]. (This is being done by several professional society publishers, but not yet by any commercial ones.) This would get libraries out of the journal distribution and archiving business (except as licensing agents, to be discussed below) and allow for drastic reductions in library budgets.

Eliminating print editions would allow for some reduction in costs of publishers (even if they kept their current expensive editing system), so they have a financial incentive to do it. In digitization, they would have to spend money beyond their current budgets. The key point is that it would not be a lot of money. An earlier article [Odlyzko4] mentioned a range of digitization costs between $\$ 0.20$ and $\$ 2.00$ per page. There are now projects (such as the commercial one for book reprinting mentioned above [NYT], and the Florida Entomological Society's project described in [Walker]) that show one can obtain a high quality digital version for $\$ 0.60$ per page. To put these numbers in perspective, all publishers collectively get about $\$ 200$ million per year for mathematical journals. On the other hand, the entire mathematical literature accumulated over the centuries is perhaps 30 million pages, so digitizing it at a cost of $\$ 0.60$ per page would cost $\$ 18$ million, less than $10 \%$ of the annual journal bill. Further, this would be a one-time expense.

On the way towards eliminating print editions, publishers will have to solve a few thorny problems. One of them is interlibrary loans. Except for a few small organizations, until recently all publishers had blanket prohibitions on the use of electronic editions for interlibrary loans. This was naturally resented by librarians, who rely on such loans to satisfy a small but important and growing fraction of their clients' demands. Without the right to use electronic editions for interlibrary loans, libraries were almost uniformly unwilling to even consider abandoning print editions. Recently some large publishers have announced changes in their policies. Electronic editions of journals of those publishers 
can now be used to satisfy interlibrary loan requests, but only by printing out the requested articles and sending them out in the printed form. Libraries will thus have the same functionality as before (or even better, since there will be no need to find volumes on shelves and make photocopies). The continued prohibition on electronic delivery of the electronic version should suffice to maintain the distinction between owning and borrowing that does not naturally exist in cyberspace, and thus maintain demand for subscriptions.

Can print journals be eliminated? Previous predictions of the eclipse of printed matter by microfilm, for example, failed to come true. (See [Odlyzko1] for a brief survey and references to numerous faulty predictions in this area.) Print is certainly persistent, as has been observed many times (cf. [Crawford]). There is even a commercial publisher that is about to start selling a print edition of the Electronic Journal of Combinatorics, the most successful of the free electronic journals in mathematics. (The electronic version will remain free, and the publisher will only get rights to distribute a print version.) Yet I am convinced that printed journals are largely on their way out. I do not mean that print is on its way out. For reasons of technology and inertia, print is likely to be with us for several decades, and even proliferate, as personal computer printers improve in quality and drop in price. All that will happen is that there will be a simple substitution, the kind that eases all technological transitions [Odlyzko6]. Scholars will print articles on their personal or departmental printers instead of going to the library, photocopying those articles, and bringing the copies back to their offices to study.

The transition to electronic distribution and storage should not take too long. There is tremendous inertia in academia, with some scholars swearing that nothing can substitute for browsing of bound printed journals. However, this resistance can be overcome. We already have examples of academic libraries in which efficient document delivery (from the library's own collections) has drastically reduced physical visits to the library by faculty and students. Further, network effects will be playing an increasing role. More material available in electronic formats and increasing linking of digital forms of articles will all be making it much more attractive to browse on a screen and print out articles for careful study. For example, in mathematics, the two main reviewing publications, Mathematical Reviews and Zentralblatt für Mathematik, whose electronic forms are catching on much faster [AndersonDR] (for obvious reasons of much greater efficiency) than online versions of primary research journals, are beginning to offer links to articles being reviewed. Publishers will surely help this move by making the electronic versions more attractive than print ones. They are already beginning to provide links to references, and making online versions of articles available earlier than the print editions. At some point they will surely also increase the prices of print editions (compared to the online ones), and perhaps 
lengthen print publication backlogs. Eventually, enough libraries will agree to eliminate print subscriptions that they will be phased out. (As an intermediate step, they might be farmed out to specialized inexpensive publishers to produce out of the electronic versions.) What I am predicting is that publishers, who used to resist electronic publishing, will, out of self-interest, play the role of the forcing agents that accelerate natural technological transitions [Odlyzko6].

The elimination of print editions of journals will eventually reduce publishers' costs. (Even though they have yet to concede that acceptable quality can be obtained in electronic publishing for $10 \%$ of the current print costs, they do admit that savings of 20-30\% can be obtained by elimination of printing and distribution costs.) Most important, this step will reduce library costs and relieve the cost pressures on academic information systems. Thus the decisive steps towards eliminating print versions of journals are likely to be taken by academic decision makers, the deans and presidents, when they realize how much can be saved.

What about librarians? I expect they would adjust easily to a paperless journal environment. First of all, transition would be gradual. While there is inertia among scholars, there is also a much more understandable inertia in the library system, given the huge accumulated print collections. These collections will have to be maintained until the slow conversion to digital format is completed. (And some materials will never be converted.) Further, there may well be a revival of scholarly monograph publishing, which has been getting squeezed out of library budgets by journals. (It is hard to forecast what effect this will have on the libraries, though, since the number of monographs published is likely to increase, but many of them will be distributed electronically.) The main job losses will be in the lessskilled positions (with the part-time student assistants who check out and reshelve material going first). Reference librarians are likely to thrive, although their job titles may not mention the library. After all, we will be in the Information Age, and there will be much more information to collect, classify, and navigate. Information specialists are likely to abound, and to have much more interesting jobs.

Although there will be many opportunities, librarians will have to compete to retain their preeminence as information specialists [Odlyzko5], and operate in new ways. However, there are two other jobs that they are also well-positioned to retain. One if that of negotiating electronic access licenses. The other is that of enforcing access restrictions.

It is worth emphasizing that if the publishers do succeed in their approach, and disintermediate the librarians while retaining their revenues and profits, the resulting system is likely to be much superior to the present one. Defenders of the current libraries tend to come from top research universities, which do have excellent library collections. That is an exception, though. Most scholars, and an overwhelming 
majority of the population, make do with very limited access to those precious storehouses of knowledge. (There is an illuminating graph in [GriffithsK], reproduced as Fig. 9.4 on p. 202 in [Lesk], that shows library usage decreasing rapidly as the effort to reach the library grows, even on a single campus. For the bulk of the world's population, little is available.) Electronic publishing promises far wider and superior access. I am not forecasting a new age of universal enlightenment, with the couch potatoes starting to read scholarly articles. However, there will be growth in usage of scholarly publications by the general public. The informal associations devoted to discussions of medical problems (those on AIDS present the best example) show how primary research material does get used by the wide public if it is easily available. For scholars alone, there will be a huge increase in productivity with much easier access to a wider range of information.

The basic strategy of the publishers, faced with pressure to reduce costs, is to disintermediate the libraries. There is nothing nefarious in this approach. As we move towards the information age, different groups will be vying to fill various rapidly evolving ecological niches. After all, many scholars are proposing that they and the librarians disintermediate the publishers, while others would bypass librarians and publishers both, and handle all of primary research publishing themselves. In this environment, some of the potentially extremely important players might be Kinko's copy shops. They may end up disintermediating the bookstores and libraries, by teaming up with publishers to print books on demand. They might also disintermediate the publishers, by making deals directly with authors and their agents.

\section{Fairness and the new economics of information goods}

The previous section outlined the strategy that established publishers appear to be pursuing or likely to pursue. Here we discuss the tactics. There are extensive fears and complaints about the pricing and access policies publishers offer for their electronic journals, as can be seen in the messages in [LIBL, NSPI]. Many of these concerns are likely to be allayed with time, as they are natural outcomes of a move towards a new technological and economic environment. By negotiations, compromise, and experiment, librarians and publishers will work out standard licensing terms that they and scholars can live with. As one example, there is great concern among librarians and scholars about access to electronic journal articles once a subscription is canceled. This is clearly an issue, but one that can be solved through negotiations.

Some issues that are raised by librarians will not go away. The basic problem with information goods is that marginal costs are negligible. Therefore pricing according to costs is not viable, and it is 
necessary to price according to value. What this means is that we will be forced into new economic models. Many people, especially Hal Varian [Varian], have been arguing for a long time that we will see much greater use of methods such as bundling, differential quality, and differential pricing. (See also [Odlyzko2, Odlyzko3, ShapiroV].) Unfortunately this will increase complaints about unfairness [Odlyzko3]. Many of the prices and policies will seem arbitrary. That is because they will be largely arbitrary, designed to make customers pay according to their willingness and ability to pay. The current U.S. airline pricing practices are a good example of the practices that work well in providing service to a wide spectrum of users with varying needs. However, those practices are universally disliked. That may also be the fate of scholarly journal publishing in cyberspace.

Pricing according to value means different prices for different institutions. Hollywood rents movies to TV networks at prices reflecting the size and affluence of that network's audience, so that a national network in Ireland will pay much more than that of Iceland, but much less than one of the large U.S. networks. We can expect prices of electronic scholarly journals to be increasingly settled by negotiations. The consolidation of publishers as well as libraries (through consortia) will help make this process manageable.

There is unhappiness among scholars and librarians about restrictions on usage of some electronic databases, such as limiting the number of simultaneous users, or restricting usage to a single workstation inside the library. The preferred method of access is, of course, from the scholar's office. However, that is precisely the point; to offer a more convenient version (such as one available without restrictions from any place on campus) for a high price, and a less convenient version (that requires a physical visit to the library, and possibly waiting in line) for a lower price. Such techniques are likely to proliferate, and a natural function for libraries will be to enforce restrictions imposed by publishers. We can already see this in the license conditions for hybrid journals that appear both in print and electronic formats. Publishers of such journals almost universally allow only the print version to be used for interlibrary loans. Although no publisher has explained clearly the rationale for this restriction, it is easy to figure out its role. Obtaining a copy of the paper article is slow, cumbersome, and expensive, and this serves to deter wide use of interlibrary loans as substitutes for owning the journal. If interlibrary loans of electronic versions were allowed, though, the borrower would be in almost the same position as a subscriber. Even if only paper copies of electronic versions of an article were allowed, the ease of making the copy from the digital form and mailing it out would make interlibrary loans much faster and less expensive, and that might undermine the market for subscriptions.

Artificial restrictions in order to maintain subscriptions are becoming much more obvious in cy- 
berspace than in print, but are not new. For example, even a casual examination shows that the Copyright Clearance Center (CCC) and the copyright litigations of the last two decades have practically no economic value to publishers aside from restricting photocopying and thus maintaining the subscriber base. In the fiscal year ending June 30, 1997, CCC paid \$35 M to copyright holders from the fees it collected. Not all this money was for scholarly publishing, and even if it were, it is tiny compared to total revenues in the U.S. for scholarly publishers, which amount to several billion dollars per year. Thus all the legal attacks on supposedly illicit photocopying and the demands for CCC fees provide little additional revenue. However, they do serve to discourage dropping of subscriptions, by making copying more expensive and more cumbersome.

Many scholars have run into problems with obtaining permission to republish their works in collected papers volumes and the like, with reprint fees often being demanded. Yet such fees bring in trivial amounts of money. Some publishers, such as the American Economic Association [Getz] and $\mathrm{ACM}$, grant blanket permissions for copying for educational use, as they have decided that the costs of handling all the copy requests were higher than the revenue derived from that activity. Thus this is another case of a barrier that exists not to increase revenues directly, but to discourage copying.

A major concern of librarians and scholars alike is that publishers will move towards a "pay-perview" model [Kiernan2]. There is little evidence of this happening, and on balance, just the opposite is occurring. There is spread of consortium licensing, in which a publisher licenses all its electronic journals to all the institutions in a region, state, or even country (with the United Kingdom taking the lead in national licensing). This was to be expected. While there are some economic models that favor pay-per-view [ChuangS], and such pricing approaches are likely to be used in some fraction of cases, to deal with unusual needs, subscriptions, bundling, and site licensing are likely to dominate. This conclusion is supported by standard economic models (cf. [BakosB, Odlyzko3, Varian]). It is also supported by empirical evidence of people's aversion to pay-per-view (cf. [FishburnOS]) and by estimates of scholars' willingness to pay for information as individuals [Hunter, Odlyzko1].

There are likely to be "pay-per-view" options, but they will probably be of marginal importance, just for dealing with demand from those who do not fit into the large classes covered by some subscription or site-license model. A major reason for this is "sticker shock." Recall that the typical article brings its publishers revenues of about $\$ 4,000$. On the other hand, all studies that have been carried out suggest that such an article is read, even if superficially (i.e., going beyond just glancing at the title page and abstract) by a couple of hundred scholars. This is also consistent with data from the Ginsparg archive, where on average a paper is downloaded on the order of 150 times in its first two years there. 
If we assume 200 readers, then to obtain the current $\$ 4,000$, the charge for "pay-per-view" would have to be $\$ 20$. I predict that few scholars would be willing to pay that much, especially for an article they had only seen the abstract for, even if the money came from their grants or departmental budgets. Of course they effectively do pay that much now, but the charges are hidden. (In fact, their institutions are paying $\$ 60$ for each article read, of which $\$ 20$ goes to the publisher, and $\$ 40$ to internal library costs.) A shift to "pay-per-view" would expose the exorbitant costs of the current system.

Bundling, site licensing, and consortium pricing are all strategies that enable publishers to increase their revenues by averaging out the different valuations that separate readers or libraries place on articles or journals. Many librarians regard consortia as advantageous because they supposedly provide greater bargaining power and thus lower prices. However, they are more likely to be helpful to publishers in maximizing their revenues. Consider a simple example of a library consortium formed by three institutions, call them A, B, and C. Suppose that A is a major research university, B a big liberal arts school with some research programs, and $\mathrm{C}$ a strictly teaching school. Consider a publisher of the (fictional) Journal of Zonotopes (JZ). Suppose the annual institutional subscription is $\$ 2,000$, and currently only A receives it. Further, suppose that B and C used to subscribe, but stopped once the price exceeded \$1,000 a year (for B) and \$200 (for C). Thus the publisher may well conclude that B and C might still be willing to pay $\$ 1,000$ and $\$ 200$ per year for $\mathrm{JZ}$, respectively. If the publisher were to stick to the policy of a uniform price for each institution, it could not gain anything by lowering JZ's price, and would risk losing A's subscription by raising it. Suppose that instead the publisher offers the consortium of $\mathrm{A}, \mathrm{B}$, and $\mathrm{C}$ a deal in which for a total price of $\$ 2,500$ per year, A continues to receive a print copy of JZ, and all three schools get unrestricted access to the electronic version. Even if the faculty and students of schools B and C value the electronic version of JZ at half of the print value, and those of A place no value on the digital format, the total value of the package to the three institutions would be $\$ 2,600$ per year, and so collectively they would be likely to spend the extra $\$ 500$.

To pursue the example above in greater detail, let us note that the attractiveness of the consortium offer is much greater than presented above if one also considers internal library costs. Institution A is really valuing $\mathrm{JZ}$ at $\$ 6,000$ or more, since those are its total costs associated with the journal, while $\mathrm{B}$ and $\mathrm{C}$ value it at $\$ 3,000$ and $\$ 600$, respectively. Thus (even ignoring possible savings that A could realize by dropping its print version), the consortium of $\mathrm{A}, \mathrm{B}$, and $\mathrm{C}$ might be willing to pay $\$ 3,000$ or more for the package. There are costs associated with negotiating the license, providing assistance in accessing the electronic version of the journal, and so on, but those costs are far smaller than those associated with handling physical collections. 
The low marginal costs of providing digital information makes it possible to distribute that information widely. If some benefactor offered to purchase for Smith College, say, all the materials that Harvard acquires, this would bankrupt Smith, as it would not be able to pay for proper handling of the huge mass of material. On the other hand, an offer of electronic access to all the materials that Harvard has access to could be provided inexpensively. What we are likely to see with the spread of library consortia is much wider access to information than we ever had before. National licensing plans are the extreme example of this, with everybody inside a country getting access to all of a publisher's material.

Bundling is likely to be widespread. Several publishers already offer their electronic journals in a single package, with no chance for purchasing access to a subset. This minimizes administrative costs, but more important, again helps take advantage of uneven preferences for different journals to obtain higher revenues. It also has the advantage of protecting publishers from the subversive influence of preprints. Several areas, and theoretical high energy physics in particular (since it has relied on the Ginsparg archive the longest), might already be willing to give up most of their journals, if hard economic times came, and academic decision makers came to departments with offers of the type "Either you give up your journals, or you give up three postdocs." In most areas, though, such a move is not feasible, since the preprint culture is not sufficiently developed. Now if the journals in theoretical high energy physics only come in a package with other journals from less advanced fields, then an offer like that above cannot be made. Thus bundling can serve the publishers' economic interests in retarding evolution of scholarly publishing to the rate of the slowest area.

Scholarly publishers are consolidating, with Elsevier, already the largest player in this market, in the forefront of the acquisition and merger wave. The publishers' market power may be counterbalanced, though, by the rise of library consortia. How the publisher oligopoly will interact with purchaser cartels will be an interesting phenomenon to watch.

\section{Will it work?}

Will the publishers succeed in disintermediating the libraries, and preserving their revenues? There are two problems they face. One is a short-term one. While electronic publication will eventually reduce the expenses of both publishers and libraries, right now it is raising those expenses, as both parties have to handle print and digital media at the same time. The other problem, the longer-term one, is that publisher revenues are far greater than is necessary to provide quality sufficient for primary publications. The manuscripts prepared by authors have been improving, to the point that all the copy editing and typesetting that publishers contribute is of diminishing value. Furthermore, in spite of the 
attempts of some publishers, there is no way to stop the preprint tide. The free circulation of preprints offers so many advantages to scholars that it is only a matter of time until they become universal. To survive in the long run, publishers will have to contribute more that is of real value. They are starting to do so by adding links to their electronic articles and similar measures. I suspect they will have to do a lot more. Until they do, they are vulnerable. Their main danger will come not from competition by Kinko's, but from a change in perceptions by administrators.

The analogy with Encyclopaedia Britannica might serve to illuminate the danger. To quote from [EvansW] again,

Judging from their initial inaction, Britannica's executives failed to understand what their customers were really buying. Parents had been buying Britannica less for its intellectual content than out of a desire to do the right thing for their children. Today when parents want to "do the right thing," they buy their kids a computer.

Nontraditional methods for information dissemination (preprints, but also email, Web pages, and so on) are growing in importance. At some point the administrators in charge of libraries may decide that "doing the right thing" for their faculty and students means redirecting resources away from traditional expensive journals.

Acknowledgements: I thank Stevan Harnad and the the other members of the American Academy of Arts and Sciences study group on transition from paper for their comments. 


\section{References}

[AndersonDR] N. D. Anderson, K. Dilcher, and J. Rovnyak, Mathematics research libraries at the end of the twentieth century: A report on the 1996 AMS-IMS-MAA survey, available at $\langle$ http://wsrv.clas.virginia.edu/ jlr5m/survey/survey.html $\rangle$. An abbreviated version published in Notices Amer. Math. Soc. 44 (Dec. 1997), 1469-1472, available at $\langle$ http://www.ams.org $\rangle$.

[ARL] Association of Research Libraries, Statistics and Measurement Program, $\langle$ http://www.arl.org/stats/index.html $\rangle$.

[BakosB] Y. Bakos and E. Brynjolfsson, Aggregation and disaggregation of information goods: Implications for bundling, site licensing and micropayment systems, in Internet Publishing and Beyond: The Economics of Digital Information and Intellectual Property, D. Hurley, B. Kahin, and H. Varian, eds., MIT Press (1997). To appear. Available at $\langle$ http://www.gsm.uci.edu/ bakos $\rangle$.

[Beschler] E. F. Beschler, A commercial publisher's point of view, Notices of the Amer. Math. Soc. 45(10) (Nov. 1998), 1333-1343. Available at $\langle$ http://www.ams.org/notices/199810/199810-toc.html〉.

[ChuangS] J. C.-I. Chuang and M. A. Sirbu, Network delivery of information goods: Optimal pricing of articles and subscriptions, in Internet Publishing and Beyond: The Economics of Digital Information and Intellectual Property, D. Hurley, B. Kahin, and H. Varian, eds., MIT Press (1997). To appear. Available at $\langle$ http://www.epp.cmu.edu/ chuang $\rangle$.

[Crawford] W. Crawford, PaperPersists: Why physical library collections still matter, Online, Jan. 1998, 〈http://www.onlineinc.com/onlinemag/JanOL98/crawford1.html〉.

[EvansW] P. B. Evans and T. S. Wurster, Strategy and the new economics of information, Harvard Business Rev. (Sept.-Oct. 1997), pp. 71-82.

[FishburnOS] P. C. Fishburn, A. M. Odlyzko, and R. C. Siders, Fixed fee versus unit pricing for information goods: competition, equilibria, and price wars, First Monday, vol. 2, no. 7 (July 1997), 〈http://www.firstmonday.dk/〉. Also to appear in Internet Publishing and Beyond: The Economics of Digital Information and Intellec- 
tual Property, D. Hurley, B. Kahin, and H. Varian, eds., MIT Press. Available at $\langle$ http://www.research.att.com/ amo $\rangle$.

[Getz] M. Getz, Electronic publishing in academia: An economic perspective, in Technology and Scholarly Communication, R. Ekman and R. Quandt, eds., Univ. Calif. Press, 1998. To appear. Available at $\langle$ http://arl.cni.org/scomm/scat/index.html $\rangle$.

[Ginsparg] P. Ginsparg, Winners and losers in the global research village, available at $\langle$ http://xxx.lanl.gov/blurb/pg96unesco.html $\rangle$.

[GriffithsK] J.-M. Griffiths and D. W. King, Special Libraries: Increasing the Information Edge, Special Libraries Assoc., 1993.

[Guthrie] K. M. Guthrie, JSTOR: The development of a cost-driven, value-based pricing model, in Technology and Scholarly Communication, R. Ekman and R. Quandt, eds., Univ. Calif. Press, 1998. To appear. Available at $\langle$ http://arl.cni.org/scomm/scat/index.html $\rangle$.

[Harnad] S. Harnad, Scholarly skywriting and the prepublication continuum of scientific inquiry, Psychological Science 1 (1990), pp. 342-343. Reprinted in Current Contents 45 (November 11, 1991), pp. 9-13. Available at $\langle$ ftp://ftp.princeton.edu/pub/harnad/Harnad/HTML/harnad90.skywriting.html $\rangle$.

[HitchcocCH] S. Hitchcock, L. Carr and W. Hall, Web journals publishing: a UK perspective, in Serials, Nov. 1997. Available at 〈http://journals.ecs.soton.ac.uk/uksg.htm〉.

[Hunter] K. Hunter, The effect of price: Early observations, in Technology and Scholarly Communication, R. Ekman and R. Quandt, eds., Univ. Calif. Press, 1998. To appear. Available at $\langle$ http://arl.cni.org/scomm/scat/index.html $\rangle$.

[ICOLC] International Coalition of Library Consortia, $\langle$ http://www.library.yale.edu/consortia/ $\rangle$.

[Kiernan1] V. Kiernan, University libraries debate the value of package deals on electronic journals: Some see a way to meet professors' needs; others say publishers are protecting profits, The Chronicle of Higher Education, Sept. 12, 1997, pp. A31-A33.

[Kiernan2] V. Kiernan, Paying by the article: Libraries test a new model for scholarly journals, The Chronicle of Higher Education, Aug. 14, 1998. 
[Lesk] M. Lesk, Practical Digital Libraries: Books, Bytes, and Bucks, Morgan Kaufman, 1997.

[LIBL] Liblicense: licensing digital information, discussion list archive, available at $\langle$ http://www.library.yale.edu/ llicense $\rangle$.

[Licklider] J. C. R. Licklider, Libraries of the Future, MIT Press, 1965.

[Melcher] R. A. Melcher, Dusting off the Britannica, Business Week, Oct. 20, 1997, pp. 143 and 146.

[NSPI] Newsletter on Serials Pricing Issues, published electronically at Univ. of North Carolina, available at URL $\langle$ http://sunsite.unc.edu/reference/prices/prices.html $\rangle$.

[NYT] New York Times, June 4, 1998. A brief note on p. G3, "A high-tech rescue for out-ofprint books."

[Odlyzko1] A. M. Odlyzko, Tragic loss or good riddance? The impending demise of traditional scholarly journals, Intern. J. Human-Computer Studies (formerly Intern. J. Man-Machine Studies) 42 (1995), pp. 71-122. Also in the electronic J. Univ. Comp. Sci., pilot issue, 1994, 〈http://hyperg.iicm.tu-graz.ac.at $\rangle$. Available at $\langle$ http://www.research.att.com/ amo $\rangle$.

[Odlyzko2] A. M. Odlyzko, On the road to electronic publishing, Euromath Bulletin, vol. 2, no. 1 (June 1996), pp. 49-60. Available at 〈http://www.research.att.com/ amo.

[Odlyzko3] A. M. Odlyzko, The bumpy road of electronic commerce, in WebNet 96 - World Conf. Web Soc. Proc., H. Maurer, ed., AACE, 1996, pp. 378-389. Available at $\langle$ http://www.research.att.com/ amo $\rangle$.

[Odlyzko4] A. M. Odlyzko, The economics of electronic journals, First Monday 2(8) (August 1997), 〈http://www.firstmonday.dk/ $\rangle$. Also to be published in Technology and Scholarly Communication, R. Ekman and R. Quandt, eds., Univ. Calif. Press, 1998. Available at $\langle$ http://www.research.att.com/ amo $\rangle$.

[Odlyzko5] A. M. Odlyzko, Silicon dreams and silicon bricks: the continuing evolution of libraries, Library Trends 46 (no. 1) (Summer 1997), pp. 152-167. Available at $\langle$ http://www.research.att.com/ amo $\rangle$. 
[Odlyzko6] A. M. Odlyzko, The slow evolution of electronic publishing, in Electronic Publishing - New Models and Opportunities, A. J. Meadows and F. Rowland, eds., ICCC Press, 1997, pp. 4-18. Available at 〈http://www.research.att.com/ amo $\rangle$.

[ShapiroV] C. Shapiro and H. R. Varian, Information Rules: A Strategic Guide to the Network Economy, Harvard Business School Press, 1998.

[TenopirK] C. Tenopir and D. W. King, The Transformation of Scholarly Journals: 20 Year Trends in the Economics, Use, and Information Seeking Patterns of Scientific Print and Electronic Scholarly Journals, Washington, D.C.: Special Libraries Association, 1998. To be published.

[Varian] H. R. Varian, Pricing information goods, available at URL $\langle$ http://www.sims.berkeley.edu/ hal/people/hal/papers.html $\rangle$.

[Walker] T. J. Walker, Free Internet access to traditional journals, Amer. Scientist 86(5) (Sept-Oct 1998), pp. 463-471. Available at 〈http://www.amsci.org/amsci/issues/TOC98/TOC98-09/contents.html〉. 